\title{
Empowerment of rural farmers through information sharing using inexpensive technologies
}

\author{
M. Louise Iraba \\ Department of Computer Science \\ University of the Western Cape \\ Cape Town, South Africa \\ $+27219593010$ \\ 2960564@uwc.ac.za
}

\author{
I.M. Venter \\ Department of Computer Science \\ University of the Western Cape \\ Cape Town, South Africa \\ $+27219593008$ \\ iventer@uwc.ac.za
}

\begin{abstract}
This paper discusses how to empower rural farmers to do business by means of inexpensive mobile technologies. In particular, the aim is to take advantage of the inexpensive features of low-end mobile phones to access market related information and to allow farmers to promote their commodities competitively.

The research targeted rural Transkei farmers in the Eastern Cape. The farmers' requirements were identified and a prototype for a low- as well as high-end mobile environment was designed to address these requirements.

The following features were effected: registration of users, posting of commodities, retrieval of information, and communication with others. The access to the system is through a website (on the phone or a personal computer) or by means of unstructured supplementary service data.

The prototype was implemented and tested. The users found the technology easy to use.
\end{abstract}

\section{Categories and Subject Descriptors}

K.4.4. [Computer and society]: Electronic commerce-Distributed commercial transactions.

\section{General Terms}

Design, Economics, Human Factors

\section{Keywords}

Index Terms - mobile computing, unstructured supplementary service data, short message service, website, commodities, farmers, Information Communication Technology for development.

\section{INTRODUCTION}

Information communication technology is ubiquitous and plays an important role in almost all aspects of modern society. However the uptake of these technologies in the African society differs remarkably between urban and rural areas. Technologies that are abundant in urban areas might not be affordable or possible to use in rural areas where the majority of the population are low-income

Permission to make digital or hard copies of all or part of this work for personal or classroom use is granted without fee provided that copies are not made or distributed for profit or commercial advantage and that copies bear this notice and the full citation on the first page. To copy otherwise, or republish, to post on servers or to redistribute to lists, requires prior specific permission and/or a fee.

SAICSIT '11, October 3-5, 2011, Cape Town, South Africa. Copyright (C) 2011 ACM 978-1-4503-0878-6/11/10... \$10.00 earners and their settlements are highly dispersed thus the population density is low [1].

Currently the use of cell phones in rural area is mostly limited to communication between families and friends. According to the World Bank, the mobile phone is a strategic tool that can reduce poverty and facilitate economic development of remote rural areas [2].

In general, rural smallholder farmers invest considerable time, effort and money in agriculture but their income is low compared to the income of the buyers and brokers (intermediary sellers) of their produce. However these intermediate sellers are their only means to the market [3]. Research shows that in general rural farmers of the Eastern Cape determine the price of their commodities based on their relationship with the buyer of their goods [4].

The question that can be raised is: Will mobile technologies create opportunities for rural farmers to promote their agricultural businesses cost effectively? To articulate this question, we can ask: How can farmers be empowered to advertise their produce and be put into contact with potential clients? How can inexpensive mobile technologies be harnessed to provide market related information to rural farmers? And finally: How can the uptake of this technology be promoted?

Mobile communication is very popular and affordable in rural areas [5]. The cell phone is a valuable tool that has many features but it is under-utilised especially in rural areas where it is mostly used for social interaction [6]. This already existing usage of mobile technology can be harnessed to improve and empower the lives of rural farmers. If they could access and share information relevant to their business practices and in so doing be introduced to other information on the internet, this can raise their level of education [7].

Mobile phone related technologies have been applied in other projects aimed at developing rural communities. Some of the important projects are:

- Wouters, et al. [8] worked on a home based health care system in South African rural communities. They proposed a patient monitoring system using Unstructured Supplementary Services Data (USSD) technology allowing caregivers to use mobile phones to provide health information and enable clinical sisters to have instant access 
to the patient's vital signs via a desktop computer.

- In the project "Linking Farmers to Markets through Modern Information and Communication Technology in Kenya" [9] the researchers came up with an idea of creating rural based market information points and district level market information, in order to link local entrepreneurs and traders. This involved mobile phone SMS communication (in partnership with a leading Kenyan mobile operator Safaricom Limited) to deliver information by means of Interactive Voice Response (IVR) to farmers. Where Mukhebi et al. used IVR this project used USSD for querying the database.

- The M-pesa system, which was launched in March 2007 in Kenya, has also been adopted and introduced in South Africa in May 2010 under the auspices of Nedbank and Vodacom. M-pesa provides money transfer banking services enabling people without bank accounts to deposit and withdraw money from agents using cell phones [10]. This type of project empowers rural communities.

Questionnaires were administered and some interviews were conducted with farmers from the Eastern Cape with the objective to obtain information about farming, cell phone usage and Internet accessibility in rural areas as well as the cost of these services. This information was used to design a prototype of a mobile marketing system. The prototype was designed and evaluated in terms of its usability and functionality. The researcher tested the application's compatibility with different mobile devices and web browsers.

The survey results showed that the respondent farmers do have mobile phones and have access to the internet but they do not use it for accessing business information. Instead they source market information by means of radio reports and contacting the shop/store to whom they want to sell or from whom they plan to buy commodities. In general respondents were conversant with cell phone services such as airtime top-up, checking balances, sending a please call me (all these services are USSD services) and they were also able to send and read SMS's.

The designed prototype consists of two parts: a web-based interface (accessible by means of a cell phone or personal computer (PC)) that allows users to post commodities, contact sellers or buyers by SMS or by using e-mail; and a USSD-based application (on a cell phone) which could be used by sellers to post their commodities and buyers to check prices and sellers' contact details. The completed prototype evaluation shows that users found it easy and convenient to use.

\section{METHODS}

Different strategies were followed to help the researcher to learn more about the people, business and information communication technology (ICT) in the areas where the information was collected. In order to understand how to ask questions from participants and obtain the desired information an integrated approach was followed (see Figure 1).
The research was done as two distinct cycles: Initially user requirements were collected, and modelled to provide a system that met the requirements. Unified modelling language (UML) was used to illustrate interactions between the system and the users and also describe the system's classes, attributes, and the relationships between the classes. During the second cycle a prototype was developed with both a website and cell phone application. The website was designed using Hypertext Preprocessor (PHP) and JavaScript as programming languages, Apache as web server, and HTTP was used as protocol for retrieving inter-linked resources. The cell phone application was designed using Java 2 Platform, Micro Edition (J2ME) and My Structured Query Language (MySQL). Both parts of the prototype access a MySQL database.

To address ethical issues of this research, permission was sought from the UWC Research Committee. Participants were informed about the project and that the information collected did not involve any sensitive information or participants' personal details.

Epistemology is the theory of knowledge thus it is "how we know what we know". Objectivism, a philosophy that maintains that all knowledge is ultimately based on perception, was the epistemological stance assumed. The theoretical perspective, postpositivism, is an amended form of positivism that recognizes human conjectures but retains the idea of objective truth. Methodology is the strategies used to collect data.

The methods are the actual tools for collecting the data, such as: interviews etc. To execute the research which straddles both quantitative and qualitative approaches, an eight-step mixed methods research model [11]was adopted:

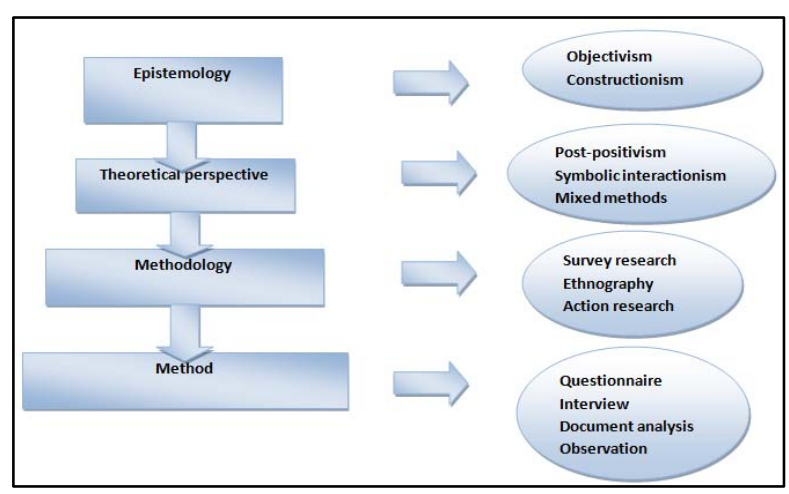

Figure 1: Methodology approach [12].

- Step 1. Clarifying the research question: The researcher discussed the problem with stakeholders and sourced the literature.

- $\quad$ Step 2: Determining whether a mixed design is appropriate: A survey was carried out to computer sciences students to obtain preliminary information and define the user requirements. Information from this investigation fed into a more detailed questionnaire administered to farmers. The data collected was analysed using quantitative methods. A prototype designed according to the farmers requirements, 
was tested by computer science students. Feedback from the students raised ideas which were pursued with interviewsthe outcome was an amended prototype.

- Step 3: Select type of research: The mixed-model research design was adopted for this research since qualitative and quantitative approaches were mixed "within ... the stages of the research process" [11]

- $\quad$ Step 4: Collect the data: This study combined both random sampling and purposive sampling of participants, during two different stages of the project. The first stage was to collect user requirements from forty-one randomly selected University of the Western Cape (UWC) students and fortysix randomly, but purposefully, selected farmers from the Transkei area. An Android cell-phone and ODK (Open Data Kit) Collect was used to collect the data in the Transkei. The second stage entailed usability testing. Random sampling was used to evaluate the prototype with students and to collect their views to improve the prototype.

- Step 5. Analyse the data: The next step was to "clean" the data - a process of identifying inconsistencies or incorrect data such as outliers. The data was analysed using Microsoft Excel and a statistical package for social sciences (SPSS) and the results were presented in tables and graphs.

- Step 6. Interpret the data: The next step was to find what results were significant and to interpret it.

- Step 7. Validate the data: Triangulation is when more than one method of data capturing is used and the results from these methods are compared to check its validity. Both qualitative and quantitative data were collected with questionnaires (closed -and open-ended questions were posed in the questionnaire). The responses of the questionnaire were validated through interviews.

- $\quad$ Step 8. The final step was to draw conclusions and write a report [11]. It was found that mobile technologies create opportunities for rural farmers to promote their agricultural businesses. A report (Masters thesis) based on the whole process, is being written.

\section{RESULTS}

The investigation within the farming community showed that access to relevant information is difficult, time consuming and costly and in the long run affects their business growth. Their major channel of information is the radio and information retrieved from local shops. Most of the rural farmers have cell phones and are conversant with the basic functions such as making a phone call, sending an SMS, sending a please call me.A few are able to access the internet through their mobile phones.

A prototype was designed to meet the requirements of rural farmers. Figure 2 depicts the design and Figure 3 shows a few of the cell phone application's steps, namely: to look for sellers details and how to contact them. From the website (see Figure 5) a contact can be selected and by clicking a SMS or an e-mail can be sent.

To get feedback on how to improve the prototype it was demonstrated to first year computer science students. Seventy two questionnaires were handed out, however only 41 completed questionnaires were returned. Due to the low return rate, seven postgraduate students were also asked to evaluate the prototype and complete the questionnaire. To collect rich data, unstructured interviews (using probes) were conducted with ten randomly selected students.

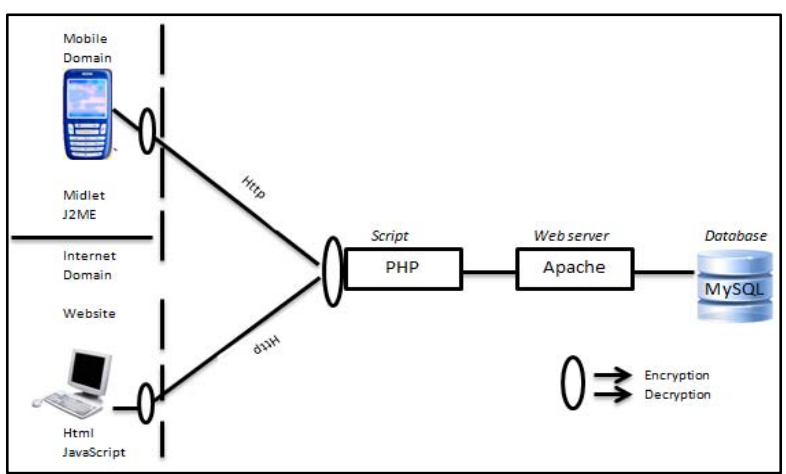

Figure 2: Schema of the prototype

\section{Website evaluation}

From the quantitative analysis it was found that most of the respondents were positive about the usability and functionality of both the PC and cell phone websites. The respondents felt it was easy to negotiate the website $(19 \%$ said it was very easy, while $47 \%$ said it was easy and $28 \%$ found it moderate). Only two per cent felt that the website is difficult to negotiate - the remaining five per cent did not comment.

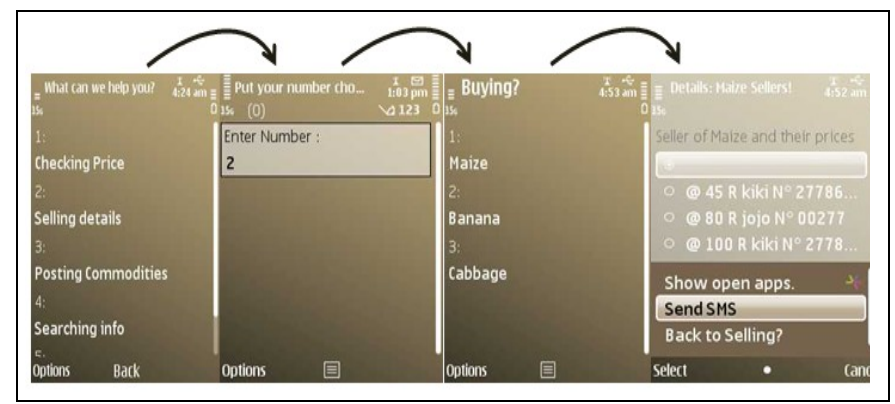

Figure 3:Sample of cell phone application

Cell phone application evaluation

The majority of users (42\%) found that the cell phone application was easy especially for sending SMS, $16 \%$ found it very easy, $33 \%$, found the application moderate especially checking price and checking sellers' details. Three per cent found it difficult or very difficult especially checking seller's details (see Figure 4).

\section{User recommendations}

Qualitative data collected indicated ways to improve the prototype. Sixty five percent of the users were satisfied with the 
prototype performance while $14 \%$ requested that the look (design) of the website should be improved. Eleven percent suggested improving functionality especially of the cell phone application.

Improvements were made to the website's functionality: ability to add commodities, to compare prices, ranking of prices and classifying by area. More images, colours for each commodity and flash functionality were added to the website. Menus were reorganised on the cell phone application.

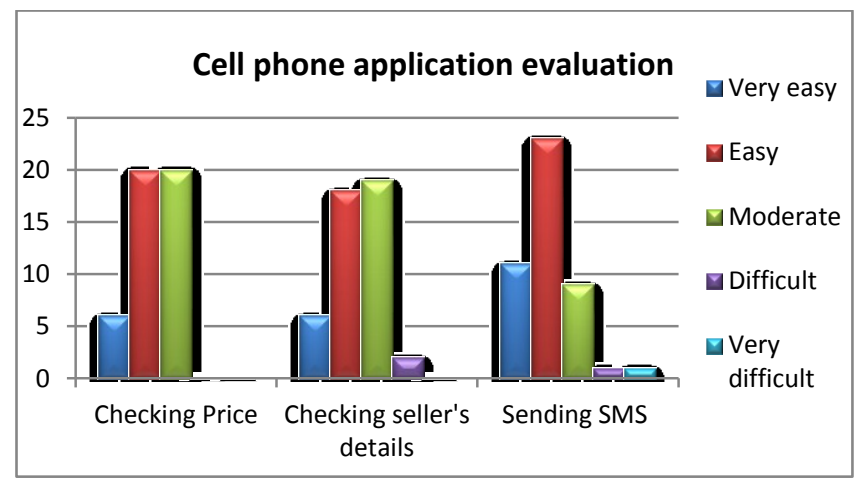

Figure 4: Cell phone application evaluation.

\section{DISCUSSION}

The research end results show that USSD (or similar inexpensive mobile technologies) allow cost effective access to market related information. Such information may enable rural farmers to improve their business by facilitating them to access market related information and information related to their farming activities. This will ensure the viability of their businesses. An inexpensive cell phone application that involves a database, a website and uses USSD technology can be implemented on a mobile phone which most of the farmers have access to and can use.

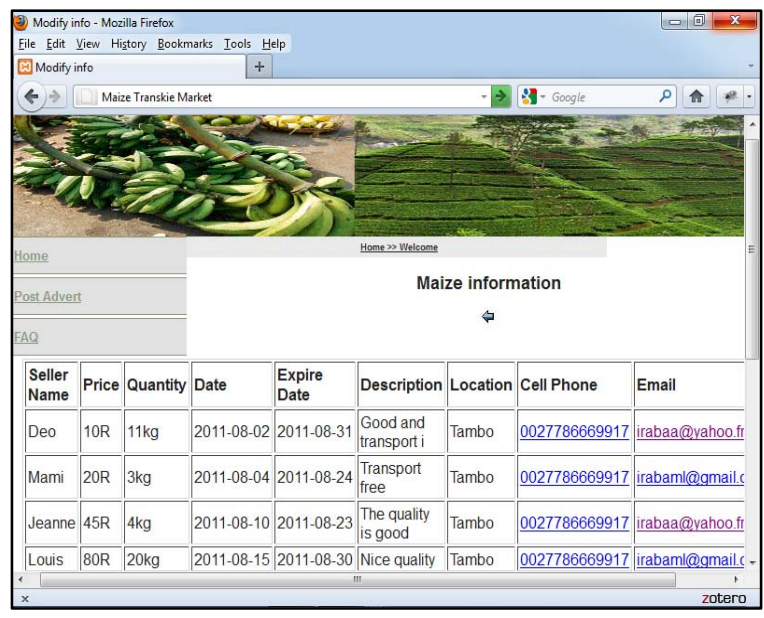

Figure 5: Sample of website application

The research conducted with Transkei farmers shows that the current means of communication and sharing and access to farming information is through radios, workshops, and newspapers which is time consuming, costly and sometimes gives inaccurate or out dated information that is not beneficial to their business. With the proposed mobile application they will be able to easily access or post information on a common database. Easy access to information, using a mobile phone (which most of the farmers own), makes it possible to get accurate and timely information. If farmers are able to advertise their produce and if they can be put into contact with potential clients, they will be able to choose the best offers and thus be empowered.

The uptake of this technology will be given impetus if the local government promotes its use and farmers' associations assist in the development and hosting of farmers' websites. The mobile service providers also stand to gain if they make such a cell phone application available to farmers.

\section{ACKNOWLEDGEMENT}

We thank William Tucker for his technical guidance and for financial support Telkom, Cisco, Aria technologies and THRIP (Technology and Human Resources for Industry Partnership), managed by the National Research Foundation (NRF). Any opinion expressed in this material are those of the authors alone.

\section{REFERENCES}

[1] F. Simba, "Broadband Access Technologies for Rural Connectivity in Developing Countries." International Journal of Research and Reviews in Computer Science, vol. 2, 2011.

[2] World Bank, Group, "Fighting Poverty with Cell Phones," http://youthink.worldbank.org, Mar. 2010.

[3] Science in Africa, Science magazine for Africa,"Ugandan farmers get connected: Information Communications Technologies deliver the power to stop poverty." 2006 .

[4] C. Phiri, "Livestock, rural livelihoods and rural development interventions in the Eastern Cape: a case study of Chris Hani, Alfred Nzo and Amathole district municipalities," 2009.

[5] A. Bhavnani, R.W. Chiu, S. Janakiram, P. Silarszky, and D. Bhatia, "The role of mobile phones in sustainable rural poverty reduction," retrieved November, vol. 22, 2008, p. 2008.

[6] N. Scott, C. Garforth, R. Jain, O. Mascarenhas, and K. McKemey, "The economic impact of telecommunications on rural livelihoods and poverty reduction: a study of rural communities in India (Gujarat), Mozambique and Tanzania," 2005.

[7] M. Oak, "Society's Influence on Education," Society's Influence on Education, Feb. 2011.

[8] B. Wouters, J. Barjis, G. Maponya, J. Martiz, and M. Mashiri, "Supporting home based health care in South African rural communities using USSD technology," AMCIS 2009 Proceedings, 2009, p. 410.

[9] A.W. Mukhebi, J. Kundu, A. Okolla, M. Wambua, W. Ochieng, and G. Fwamba, "Linking farmers to markets through modern information and communication technologies in Kenya," 2007 Second International Conference, August 20-22, 2007, Accra, Ghana, 2008.

[10] H. Bester, "M-PESA: From Kenya to South Africa". s.l. : FinMark Forum, 2010.

[11] R.B. Johnson and A.J. Onwuegbuzie, "Mixed methods research: A research paradigm whose time has come," Educational researcher, vol. 33, 2004, p. 14.

[12] M. Crotty "The foundations of social research: Meaning and perspective in the research process.", SAGE Publication,London, 1998 